\title{
Correspondence
}

\section{Detention of children is needed at times}

I am writing to thank Thomas et $a l^{1}$ for raising the issues of younger children and the authorisation of admission and treatment. The Mental Health Act 1983 is the only UK legislation that deals solely with the treatment of mental disorders and has a number of inbuilt safeguards - including the mental health tribunal, which was utilised in the case and discussed in the article - which are important factors when considering the 'least restrictive' principle. In many ways, the Mental Health Act 1983 is less restrictive than relying solely on a parent to authorise an admission, as there is a greater opportunity for the patient to have the detention independently reviewed in a timely fashion.

I wanted to raise a number of points. First, it is important to recognise that the law divides the under $18 \mathrm{~s}$ into two groups: those under 16, and those aged 16 and 17. For the first group, when assessing the ability to make decisions, the case law of Gillick is used and those who have sufficient understanding and intelligence to make their own decisions are referred to as Gillick competent. ${ }^{2}$ For the second group, the Mental Capacity Act 2005 applies and they are referred to as having capacity, in the same way as adults. It is an important distinction, and still causes much confusion.

My second point risks confusing the issue of what parents can consent to further. Thomas et al state that ' . . . a parent may not lawfully detain or authorise the detention of a child', which was the established wisdom, but this has been challenged in a recent case, named by some as Baby Bournewood. ${ }^{3}$ In this case, Judge Keehan ruled that the hospital admission of a 15-year-old child with Asperger syndrome, attention-deficit hyperactivity disorder and Tourette syndrome who was under continuous supervision and control, and who would be prevented from leaving the hospital, did not constitute a deprivation of liberty and so could be authorised by someone with parental responsibility. This flies in the face of the Cheshire West case discussed in the article.

My last point concerns the discussion about the 'doctrine of necessity'. It is also important to note that section 3(5) of the Children Act 1989 states that in an emergency or urgent situation a person who has care of the child but does not have parental responsibility may do 'what is reasonable in all the circumstances of the case for the purpose of safeguarding or promoting the child's welfare.'

John S. Watts, child and adolescent psychiatrist, South London and Maudsley NHS Foundation Trust, London, UK, email: john.watts@nhs.net

1 Thomas V, Chipchase B, Rippon L, McArdle P. The application of mental health legislation in younger children. BJPsych Bull 2015; 39: 302-4.

2 Gillick $v$ West Norfolk and Wisbech Area Health Authority [1986] AC 112.

$3 D$ (A Child) (Deprivation of Liberty) (2015) EWHC 922 (Fam).

doi: $10.1192 / \mathrm{pb} .40 .2 .106$

\section{Information for CAMHS patients about tribunals}

Thomas et al ${ }^{1}$ discussed the legal authority for detention of an 8 -year-old child. The patient exercised his right of appeal with assistance from a solicitor and an independent mental health advocate and solicitor. The authors conclude that all clinicians working in child and adolescent services require knowledge of the law in relation to treatment of mental disorders in children.

We consider it equally important that any detained children and adolescents have access to information about the process of a mental health tribunal hearing to ensure they are able to participate fully but also in the least distressing way. All information for patients about the procedure at a tribunal hearing - available via the Royal College of Psychiatrists ${ }^{2}$ or the First-tier Tribunal (Mental Health) website (www.gov.uk/ mental-health-tribunal/what-happens-at-the-hearing) - is aimed at adult patients.

To ensure developmentally appropriate information, we worked with a focus group of young people on a child and adolescent mental health service (CAMHS) in-patient unit and composed a suitable leaflet. The final version has been approved by the First-tier Tribunal (Mental Health) CAMHS panel lead judge and also by the Royal College of Psychiatrists' CAMHS Faculty lead. The leaflet is available on the College website (www.rcpsych.ac.uk/pdf/CAMHS\%20GUide\%20 to\%20Mental\%20Health\%20Tribunals\%20Feb\%202016.pdf).

We hope that this information will be of benefit to detained young people such as the child in the case report.

Sophia T. Ulhaq, ST6 doctor in child and adolescent psychiatry, The Coborn Centre for Adolescent Mental Health \& Ealing CAMHS, Middlesex, UK, email: sophia.ulhaq@elft.nhs.uk, Aneira Carter, 6th form student and Joan Rutherford, Chief Medical Member, First-tier Tribunal (Mental Health), London, UK.

1 Thomas V, Chipchase B, Rippon L, McArdle P. The application of mental health legislation in younger children. BJPsych Bull 2015; 39: 302-4.

2 Rutherford J. A guide to mental health tribunals (leaflet). Royal College of Psychiatrists, 2015. Available at: http://www.rcpsych.ac.uk/ healthadvice/problemsdisorders/guidementalhealthtribunals.aspx

doi: $10.1192 / p b .40 .2 .106 a$

\section{Mobile telephone apps first need data security and efficacy}

The recent article on mobile telephone software applications (apps) in mental health practice ${ }^{1}$ highlights many potential benefits of smartphone apps for mental health but also inadvertently demonstrates the challenges beyond what the authors may have realised. The paper refers readers to the National Health Service (NHS) Health Apps Library (http:// apps.nhs.uk) when discussing psychological apps. However, in recent months the Library has been closed amid serious concerns that apps featured on the site may not be clinically effective ${ }^{2}$ and may suffer from both security and privacy flaws that left patient data exposed. ${ }^{3}$ This rapid change in the smartphone apps landscape came suddenly and rapidly and demonstrates how much we still do not know about using this technology for healthcare. What we do know is that a firm foundation in privacy, security and efficacy is critical. Just as we demand clinical evidence and safety data when considering a new medication, we should also demand the same high 